\title{
Isolation and Identification of Flavonoids Found in Zostera marina Collected in Norwegian Coastal Waters
}

\author{
Kjersti Hasle Enerstvedt, Monica Jordheim*, Øyvind M. Andersen \\ Department of Chemistry, University of Bergen, Bergen, Norway \\ Email: *monica.jordheim@uib.no
}

Received 23 April 2016; accepted 23 May 2016; published 26 May 2016

Copyright (C) 2016 by authors and Scientific Research Publishing Inc.

This work is licensed under the Creative Commons Attribution International License (CC BY). http://creativecommons.org/licenses/by/4.0/

(c) (;) Open Access

\begin{abstract}
In extracts of the seagrass Zostera marina, collected in coastal waters of West-Norway, fourteen different flavones and high amounts of rosmarinic acid were identified. Five of the flavones were found to be sulphated, among these were luteolin 7,3'-disulphate and chrysoeriol 7-sulphate structures previously not published with complete NMR assignments. Luteolin 7-O- $\beta-(6 "-$-malonyl) glucoside, and two other malonylated flavone compounds occurring in trace amounts, were identified for the first time in $Z$. marina. The sulphated flavones were fairly stable in slightly acidified $(0.1 \%$ trifluoroacetic acid) extracts stored for months, however, under more acidic conditions $(0.5 \%$ trifluoroacetic acid in the extracts) they were susceptible to undergo hydrolyses. When the solvents of purified fractions were removed by rotary evaporation, the sulphated flavones quickly decomposed to their corresponding aglycones due to the increased acid concentrations.
\end{abstract}

\section{Keywords}

Zostera marina, Sulphated, Flavones, NMR, Spectral Data, Characterization, Stability

\section{Introduction}

Seagrasses are marine, rooted, flowering plants with terrestrial origin [1]. There are more than 70 species of seagrasses worldwide [2], but only four species of seagrasses have been found in European waters, namely Zostera marina L. (eelgrass), Zostera noltii (dwarf eelgrass), Cymodoceanodosa and Posidoniaoceanica [1]. Two of these: Z. marina and Z. noltii, are native to Norwegian coastal waters, in addition to Z. angustifolia which is considered as a variety of Z. marina. Z. marina, the most widely distributed seagrass in Norway, is most com-

*Corresponding author.

How to cite this paper: Enerstvedt, K.H., Jordheim, M. and Andersen, Ø.M. (2016) Isolation and Identification of Flavonoids Found in Zostera marina Collected in Norwegian Coastal Waters. American Journal of Plant Sciences, 7, 1163-1172. 
mon in the southern parts of Norway, but has also been found in the northern areas [3] [4]. The marine seagrasses form an ecological and therefore paraphyletic group of marine hydrophilus angiosperms which evolved three to four times from land plants towards an aquatic and marine existence [5]. Their taxonomy is not properly solved on the species level and below mainly due to their reduced morphology. Their physiology is also not well understood due to difficult experimental in situ and in vitro conditions. Seagrasses contain several compounds which make them different from terrestrial plants; some of these compounds might be of commercial interest. Harborne and Williams work back in the 70ties [6] revealed the occurrence of flavonoid sulphates in Zostera on the basis of TLC, electrophoretic mobility, $\lambda_{\max }$ and colour in UV light, and sulphated flavonoids were found to be more common in plants than previously considered [7]. So far, more than 150 sulphated flavonoids have been found in nature [8], most of which is based on flavones or flavonols. In plants, sulphated flavonoids are reported to be involved in regulation of plant growth [9]-[11], and they might form stable complexes with other flavonoids, for example anthocyanins [11]. It is also suggested that sulphation of flavonoids represents an ecological adaptation, due to the presence of sulphated flavonoids in numerous plants growing in marine habitats [9] [12]. Flavonoids are in general known for their wide range of biological activities [13]-[18] and several studies have addressed in particular sulphated flavonoids for their anticoagulant [9] [10], anti-inflammatory, antiviral and antitumor activities [11] [19]. Relevant here are some comparative studies of luteolin and luteolin 7,3'-disulphate from extracts of Z. marina [20] [21]. The disulphated flavone showed the highest pharmacological activities explained by its higher water solubility, which facilitated the absorption of the flavonoid in the intestines causing higher concentration of the flavonoid in the blood [20]. The sulphate ester bonds to flavonoids are, however, considered as relative unstable, implying that sulphated flavonoids [7] [12] might be degraded during extraction, purification and storage. After optimization of extraction and isolation conditions, addressing in particular the impact of solvent acidity on the unstable ester bonds in mono- and di- sulphated flavones, the flavonoid and rosmarinic content of $Z$. marina collected in Norwegian seawaters are here reported for the first time. Among the fourteen different flavones which were identified, five were found to be sulphated. Two of these have never been completely assigned with NMR data before. We also report on three flavones, which have not been identified previously in Z. marina.

\section{Experimental}

\subsection{Plant Material}

Zostera marina L. was collected during spring low tide by hand at a locality close to Espegrend Marine Biological Station outside Bergen, Norway. The sample locality $\left(60^{\circ} 16^{\prime} 12.0^{\prime \prime} \mathrm{N}, 05^{\circ} 13^{\prime} 20.3^{\prime \prime E}\right)$ was situated in a small sheltered bay, influenced by fresh water from a small brook. Z. marina formed a large patch growing in fine, muddy sediment. The collected material was washed thoroughly in fresh water and air-dried. The root was separated from the rest of the plant, and the material was cut in small pieces and stored at $-20^{\circ} \mathrm{C}$, when not used. A voucher specimen has been deposited in the Herbarium BG at the University Museum of Bergen, Bergen.

\subsection{Extraction and Purification}

The seagrass was extracted 3 times with $50 \%$ aqueous methanol, after optimization of extraction conditions. The extracts were filtered through glass wool, and the methanol was removed using a rotary evaporator under reduced pressure at $27^{\circ} \mathrm{C}$, followed by partitioning with ethyl acetate. The aqueous layer, containing the flavonoids, was further concentrated and applied to an Amberlite XAD-7 column $(70 \times 5 \mathrm{~cm}$, Sigma-Aldrich, Steinheim, Germany). The flavonoids were eluted with distilled water until the fractions were colorless, and then methanol was applied for elution of adsorbed flavonoids. Obtained fractions were analyzed by analytical HPLC-DAD, and fractions containing similar qualitative flavonoid content were combined and concentrated under reduced pressure. The semi-purified plant extract was submitted to preparative HPLC to obtain purified compounds. The purified fractions were evaporated under reduced pressure at $27^{\circ} \mathrm{C}$, and were further analyzed by HRLC-MS and NMR spectroscopy.

\subsection{Stability Observations}

Approximately $50 \mathrm{mg}$ of dried Z. marina leaves was extracted with $50 \%$ methanol with $0.1 \%, 1.0 \%$ formic acid, $0.1 \%$ and $0.5 \%$ trifluoroacetic acid (TFA) for 1 hour at $25^{\circ} \mathrm{C}$. The extracts were filtered and analyzed periodi- 
cally by analytical HPLC over 3 months period, and compared with a corresponding extract containing no acid. The relative content of sulphated flavonoids in the extract was determined by peak area measurement at $360 \mathrm{~nm}$ of individual compounds, relative to the total area of all flavonoids in the sample.

\subsection{General Instrumentation}

Analytical HPLC: The Agilent 1100 HPLC system was equipped with a HP 1050 diode array detector and a $200 \times$ $4.6 \mathrm{~mm}$ inside diameter, $5 \mu \mathrm{m}$ ODS Hypersil column (Supelco, Bellefonte, PA). Two solvents, (A) water (0.5\% TFA) and (B) acetonitrile (0.5\% TFA), were used for elution. The elution profile for HPLC consisted of initial conditions with $90 \% \mathrm{~A}$ and $10 \% \mathrm{~B}$ followed by a linear gradient elution to $50 \% \mathrm{~B}$. The flow rate was 1.0 $\mathrm{mL} / \mathrm{min}$, and aliquots of $15 \mu \mathrm{L}$ were injected with an Agilent 1100 series microautosampler. The UV-Vis absorption spectra were recorded online during HPLC analysis over the wavelength range of $240-600 \mathrm{~nm}$ in steps of $2 \mathrm{~nm}$. Preparative HPLC: The system used a Gilson 321 pump equipped with an Ultimate 3000 variable wavelength detector, a $25 \times 2.2 \mathrm{~cm}(10 \mu \mathrm{m})$ Econosphere C18 column (Grace, Deerfield, IL), and the solvents (A) water $(0.1 \%$ formic acid $)$ and $(\mathrm{B})$ acetonitrile $(0.1 \%$ formic acid $)$. Following gradient was used: 0 - 5 min; $15 \%$ $20 \%$ B, 5 - $25 \mathrm{~min} ; 20 \%$ - 30\% B, $25-28 \mathrm{~min} ; 30 \%-40 \% \mathrm{~B}, 28-30 \mathrm{~min} 40 \%$ - 15\% B. The flow rate was 15 $\mathrm{mL} / \mathrm{min}$. NMR-spectroscopy: One-dimensional ${ }^{1} \mathrm{H}, 2 \mathrm{D}$ heteronuclear single quantum coherence $\left({ }^{1} \mathrm{H}-{ }^{13} \mathrm{C} \mathrm{HSQC}\right)$, heteronuclear multiple bond correlation $\left({ }^{1} \mathrm{H}-{ }^{13} \mathrm{C} \mathrm{HMBC}\right)$, double quantum filtered correlation $\left({ }^{1} \mathrm{H}-{ }^{1} \mathrm{H}\right.$ DQF COSY) and total correlation spectroscopy $\left({ }^{1} \mathrm{H}-{ }^{1} \mathrm{H}\right.$ TOCSY) experiments were obtained on a Bruker $600 \mathrm{MHz}$ instrument equipped with a cryogenic probe. Sample temperatures were stabilized at $298 \mathrm{~K}$. The deuteriomethyl ${ }^{13} \mathrm{C}$ signal and the residual ${ }^{1} \mathrm{H}$ signal of the solvent $\left(d_{6}\right.$-DMSO) were used as secondary references $(\delta 39.5$ and 2.5 from TMS, respectively).High-resolution LC-electrospray mass spectrometry (ESI ${ }^{+} / \mathrm{TOF}$ ), spectra were recorded using a JEOL AccuTOF JMS-T100LC in combination with an Agilent Technologies 1200 Series HPLC system at the following instrumental settings/conditions; Ionization mode: positive, ion source temperature $=250^{\circ} \mathrm{C}$, needle voltage $=2000 \mathrm{~V}$, desolvation gas flow $=2.0 \mathrm{~L} / \mathrm{min}$, nebulizing gas flow $=1.0 \mathrm{~L} / \mathrm{min}$, orifice1 temperature $=100^{\circ} \mathrm{C}$, orifice 2 voltage $=6 \mathrm{~V}$, ring lens voltage $=18 \mathrm{~V}$, ion guide peak voltage $=2000 \mathrm{~V}$, detector voltage $=2300 \mathrm{~V}$, acquisition range $=100-1000 \mathrm{~m} / \mathrm{z}$, spectral recording interval $=0.5 \mathrm{~s}$, wait time $=$ $0.03 \mathrm{~ns}$ and data sampling interval $=0.5 \mathrm{~ns}$. Sample was solved in a mixture of water and acetonitrile with $0.1 \%$ formic or acetic acid. The elution profile for HPLC consisted of initial conditions with $90 \%$ A (water with $0.1 \%$ formic acid) and 10\% B (acetonitrile with $0.1 \%$ formic acid), isocratic elution 0 - 2 min, followed by a linear gradient elution to $50 \%$ B (2 - $15 \mathrm{~min})$. A $50 \times 4.6 \mathrm{~mm}$ internal diameter, $1.8 \mu \mathrm{m}$ Agilent Zorbax Eclipse XDB C18 column was used for separation.

\section{Results and Discussion}

\subsection{Characterization of Zostera marina Flavones}

The HPLC profile of Zostera marina extract (Figure 1) revealed the presence of three major $(\mathbf{1}, \mathbf{4 , 8 )}$ and five minor flavones $(\mathbf{2}, \mathbf{3}, \mathbf{5}, \mathbf{7}, \mathbf{9})$ (Figure 2 and Table 1), together with higher amounts of rosmarinic acid (6). In addition, traces of six flavones (10-15) were found during HRLC-MS examinations of the extracts. Five of these flavones $(\mathbf{1}, \mathbf{2}, \mathbf{4}, \mathbf{7}, \mathbf{8})$ were substituted with sulphate groups, and the order of retention times in the HPLC reversed phase column system was found to be: disulphate $(\mathbf{1})<$ monoglucoside $(\mathbf{3})<$ monosulphate $(\mathbf{4})<$ acyl glucoside (5) < aglycone (9), here exemplified with luteolin derivatives.

As shown in Figure 3 the UV absorption spectra of luteolin 7-sulphate (4) and luteolin (9) are relative similar, and their $\mathrm{UV}_{\max }$ values are consistent with previously reported data for flavones and flavone glycosides [22], whilst the significant hypsochromic shift in the $\mathrm{UV}_{\max }$ of luteolin 7,3'-disulphate (1), is strongly indicating the presence of a sulphate group in the 3'- or 4'-position on the B-ring. Thus, introducing a sulphate group to the flavonoid A-ring, does not influence the UV absorption significantly, but sulphation in the 3'- or 4'-position on the B-ring will cause a large hypsochromic shift in band I. Thus flavonoid sulphates seem to have analogous UV spectral characteristics as their corresponding flavonoid glycosides [12].

\subsection{Stability of Sulphated Flavones}

The stability of the sulphated flavones in Z. marina extracts was investigated under various acidic conditions. The compounds were quite stable in extracts containing $0.1 \%-1.0 \%$ formic acid and in $0.1 \%$ TFA, and did not 


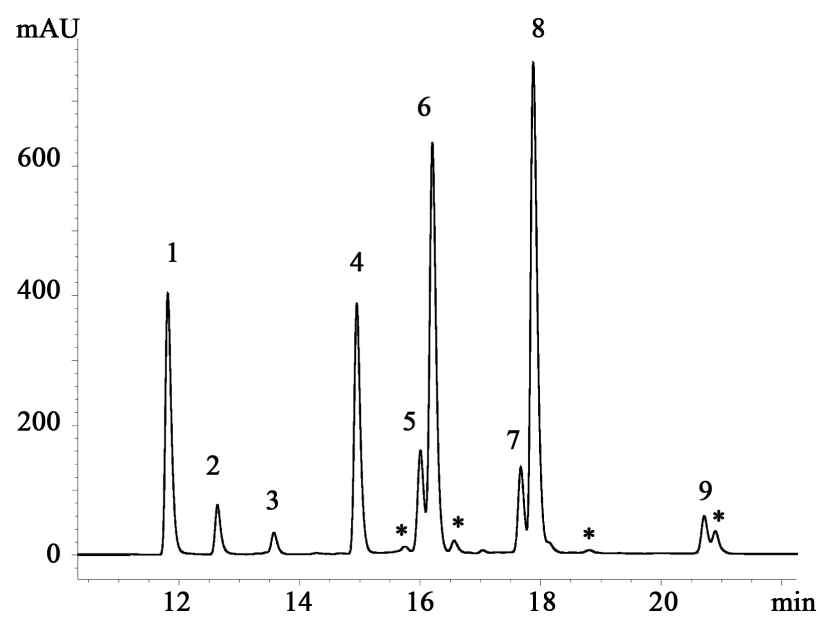

Figure 1. HPLC chromatogram of Zostera marina extract (recorded at $360 \mathrm{~nm}$ ). $1=$ luteolin 7,3'-disulphate, $2=$ diosmetin 7,3'-disulphate, $\mathbf{3}=$ luteolin 7-O- $\beta$-glucoside, 4 = luteolin 7-sulphate, $\mathbf{5}=$ luteolin 7-O- $\beta$-(6"-malonyl)glucoside, $\mathbf{6}=$ rosmarinic acid, $7=$ chrysoeriol 7 -sulphate, $8=$ diosmetin 7 -sulphate, $9=$ luteolin, ${ }^{*}$ unidentified compounds.<smiles>[R]c1ccc(-c2cc(=O)c3c(O)cc(OS(=O)(=O)O)cc3o2)cc1OS(=O)(=O)O</smiles><smiles>[R]c1ccc(-c2cc(=O)c3c(O)cc(OC4OCC5COCC4C(O)C5O)cc3o2)cc1[R]</smiles>

$\begin{array}{ll}1 & \mathrm{R}_{1}=\mathrm{OH} \\ 2 & \mathrm{R}_{1}=\mathrm{OCH}_{3}\end{array}$

$3 \quad \mathrm{R}_{1}=\mathrm{R}_{2}=\mathrm{OH}, \mathrm{R}_{4}=\mathrm{H}$

$5 \quad \mathrm{R}_{1}=\mathrm{R}_{2}=\mathrm{OH}, \mathrm{R}_{4}=$ malonyl

$10 \mathrm{R}_{1}=\mathrm{OH}, \mathrm{R}_{2}=\mathrm{R}_{4}=\mathrm{H}$

$11 \mathrm{R}_{1}=\mathrm{OH}, \mathrm{R}_{2}=\mathrm{H}, \mathrm{R}_{4}=$ malonyl

$12 \mathrm{R}_{1}=\mathrm{OH}$ or $\mathrm{OCH}_{3}, \mathrm{R}_{2}=\mathrm{OCH}_{3}$ or $\mathrm{OH}, \mathrm{R}_{4}=$ malonyl<smiles>[R]c1ccc(-c2cc(=O)c3c(O)cc(OS(=O)(=O)O)cc3o2)cc1[R]</smiles><smiles>[R]c1ccc(-c2cc(=O)c3c(O)cc(O)cc3o2)cc1[R]</smiles>

$$
\begin{array}{ll}
4 & \mathrm{R}_{1}=\mathrm{R}_{2}=\mathrm{OH}, \\
7 & \mathrm{R}_{1}=\mathrm{OH}, \mathrm{R}_{2}=\mathrm{OCH}_{3} \\
8 & \mathrm{R}_{1}=\mathrm{OCH}_{3}, \mathrm{R}_{2}=\mathrm{OH}
\end{array}
$$

$$
\begin{aligned}
9 & \mathrm{R}_{1}=\mathrm{OH}=\mathrm{R}_{2}=\mathrm{OH}, \\
13 & \mathrm{R}_{1}=\mathrm{OH}, \mathrm{R}_{2}=\mathrm{OCH}_{3} \\
14 & \mathrm{R}_{1}=\mathrm{OCH}_{3}, \mathrm{R}_{2}=\mathrm{OH} \\
15 & \mathrm{R}_{1}=\mathrm{OCH}_{3}, \mathrm{R}_{2}=\mathrm{OH}
\end{aligned}
$$

Figure 2. Structures of the flavones found in Zostera marina leaves. $\mathbf{1}=$ luteolin 7,3'-disulphate, $\mathbf{2}=$ diosmetin 7,3'disulphate, $\mathbf{3}=$ luteolin 7 - $O$ - $\beta$-glucoside, 4 = luteolin 7 -sulphate, $5=$ luteolin $7-O-\beta$ - $\left(6^{\prime \prime}\right.$-malonyl)glucoside, $7=$ chrysoeriol 7-sulphate, $\mathbf{8}=$ diosmetin 7-sulphate, $\mathbf{9}=$ luteolin, $\mathbf{1 0}=$ apigenin 7-glucoside, $\mathbf{1 1}=$ apigenin 7-(6"-malonyl)glucoside, 12 = diosmetin- or chrysoeriol 7-(6"-malonyl)glucoside, $\mathbf{1 3}=$ apigenin, $\mathbf{1 4}=$ chrysoeriol, $\mathbf{1 5}=$ diosmetin. The flavones 10-15 are only present in trace amounts in the plant extract. 


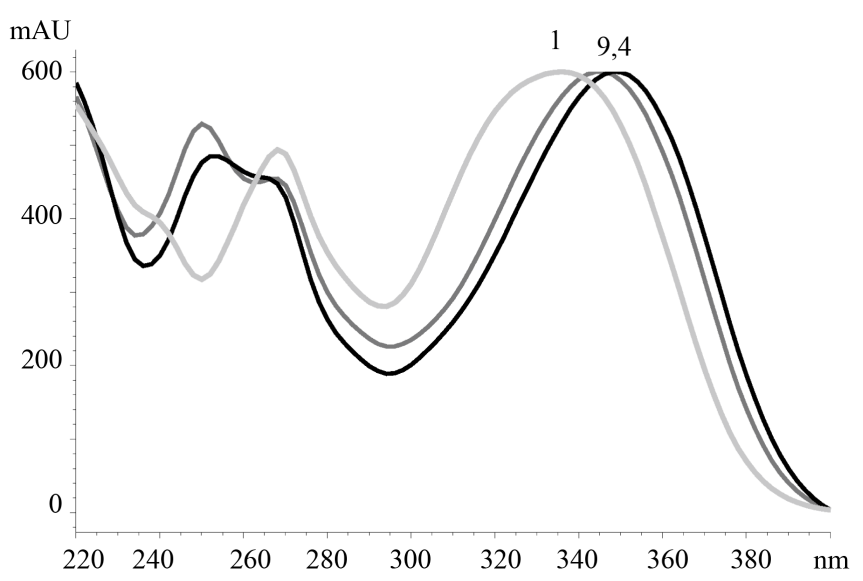

Figure 3. UV absorbance spectra for 1 (luteolin 7,3'-disulphate), 4 (luteolin 7-sulphate) and 9 (luteolin).

Table 1. Chromatographic and spectral (UV-vis and MS) data of the flavones and rosmarinic acid (6) in Zostera marina.

\begin{tabular}{|c|c|c|c|c|c|c|c|}
\hline \multirow[b]{2}{*}{ Compound } & \multicolumn{3}{|c|}{ Online HPLC } & \multicolumn{3}{|c|}{ LC-MS } & \multirow[b]{2}{*}{ Molecular formula } \\
\hline & $\begin{array}{c}\mathrm{UV}_{\max } \\
(\mathrm{nm})\end{array}$ & $\begin{array}{l}\text { Local } U_{\text {max }} \\
\quad(\mathrm{nm})\end{array}$ & $\begin{array}{c}t_{\mathrm{R}} \\
(\mathrm{min})\end{array}$ & $\begin{array}{l}{[\mathrm{M}+1]^{+} \mathrm{m} / \mathrm{z}} \\
\text { (observed) }\end{array}$ & $\begin{array}{l}\text { Fragment } \\
\mathrm{m} / \mathrm{z}\end{array}$ & $\begin{array}{c}{[\mathrm{M}+1]^{+}} \\
\mathrm{m} / \mathrm{z} \\
\text { (calculated) }\end{array}$ & \\
\hline 1 & 337 & 267 & 11.86 & 446.9725 & $367.0143,287.0578$ & 446.9692 & $\mathrm{C}_{15} \mathrm{H}_{10} \mathrm{O}_{12} \mathrm{~S}_{2}$ \\
\hline 2 & 333 & 269 & 12.70 & 460.9869 & $381.0276,301.0693$ & 460.9848 & $\mathrm{C}_{16} \mathrm{H}_{12} \mathrm{O}_{12} \mathrm{~S}_{2}$ \\
\hline 3 & 348 & 253,266 & 13.53 & 449.1086 & 287.0562 & 449.1084 & $\mathrm{C}_{21} \mathrm{H}_{20} \mathrm{O}_{11}$ \\
\hline 4 & 349 & 253,266 & 14.96 & 367.0127 & 287.0564 & 367.0124 & $\mathrm{C}_{15} \mathrm{H}_{10} \mathrm{O}_{9} \mathrm{~S}$ \\
\hline 5 & 338 & 252,266 & 15.96 & 535.1080 & - & 535.1088 & $\mathrm{C}_{24} \mathrm{H}_{22} \mathrm{O}_{14}$ \\
\hline 6 & 330 & $290(\mathrm{sh})$ & 16.18 & 361.0929 & 163.0386 & 361.0923 & $\mathrm{C}_{18} \mathrm{H}_{16} \mathrm{O}_{8}$ \\
\hline 7 & 348 & 252,266 & 17.69 & 381.0283 & 301.0719 & 381.0280 & $\mathrm{C}_{16} \mathrm{H}_{12} \mathrm{O}_{9} \mathrm{~S}$ \\
\hline 8 & 347 & 252,266 & 17.91 & 381.0283 & 301.0719 & 381.0280 & $\mathrm{C}_{16} \mathrm{H}_{12} \mathrm{O}_{9} \mathrm{~S}$ \\
\hline 9 & 346 & 250,268 & 20.77 & 287.0553 & - & 287.0556 & $\mathrm{C}_{15} \mathrm{H}_{10} \mathrm{O}_{6}$ \\
\hline $10^{*}$ & & & & 433.1140 & & & $\mathrm{C}_{21} \mathrm{H}_{20} \mathrm{O}_{10}$ \\
\hline $11^{*}$ & & & & 519.1155 & & & $\mathrm{C}_{24} \mathrm{H}_{22} \mathrm{O}_{13}$ \\
\hline $12^{*}$ & & & & 549.1242 & & & $\mathrm{C}_{25} \mathrm{H}_{24} \mathrm{O}_{14}$ \\
\hline $13^{*}$ & & & & 271.0605 & & & $\mathrm{C}_{15} \mathrm{H}_{11} \mathrm{O}_{5}$ \\
\hline $14^{*}$ & & & & 301.0701 & & & $\mathrm{C}_{16} \mathrm{H}_{12} \mathrm{O}_{6}$ \\
\hline $15^{*}$ & & & & 301.0701 & & & $\mathrm{C}_{16} \mathrm{H}_{12} \mathrm{O}_{6}$ \\
\hline
\end{tabular}

sh $=$ shoulder. ${ }^{*}$ only found in trace amounts in extracts (10: apigenin 7-glucoside, 11: apigenin 7: (malonyl)glucoside, 12: diosmetin- or chrysoeriol 7: (malonyl)glucoside, 13: apigenin, 14: chrysoeriol, 15: diosmetin).

show significant differences when compared to their storage in the corresponding neutral methanolic extract for 3 months. However, in the extract containing $0.5 \%$ TFA, the flavone sulphates $(\mathbf{1}, \mathbf{2}, \mathbf{4}, \mathbf{7}$ and $\mathbf{8})$ decomposed gradually to their corresponding aglycones $(\mathbf{9}, \mathbf{1 4}$ and $\mathbf{1 5})$ due to acid hydrolysis. The sulphated flavones were isolated and purified by preparative HPLC, and their stability in the eluate solvent (consisting of water and acetonitrile with $0.1 \%$ formic acid) were monitored by analytical HPLC. The results showed that the sulphated flavones were relative stable in this solvent with a decay of $1 \%-5 \%$ in the course of 10 days. However, when the solvent was removed by evaporation, these compounds quickly decomposed to their corresponding aglycones, due to accumulated acid concentrations. Despite the problems with instability of the sulphated flavones, we were able to obtain pure samples of $\mathbf{1}(14 \mathrm{mg}), \mathbf{4}(4 \mathrm{mg})$ and $\mathbf{7}(6 \mathrm{mg})$. 


\subsection{NMR Assignment of Luteolin 7,3'-Disulphate (1), Chrysoeriol 7-Sulphate (7) and Luteolin 7-O- $\beta-(6 "$ "-Malonyl)Glucoside (5)}

The ${ }^{1} \mathrm{H}$ NMR spectrum of compound 1 (Figure 2) showed six proton signals in the aromatic region; a pair of meta coupled protons at $\delta 6.57(1 \mathrm{H}, d, J=2.06 \mathrm{~Hz}, \mathrm{H}-6)$ and $\delta 6.98(1 \mathrm{H}, d, J=2.01 \mathrm{~Hz}, \mathrm{H}-8)$, a one proton singlet at $\delta 6.74(\mathrm{H}-3)$, and the AMX system at $\delta 6.99\left(1 \mathrm{H}, d, J=8.3 \mathrm{~Hz}, \mathrm{H}-5{ }^{\prime}\right), \delta 7.93(1 \mathrm{H}, d, J=2.34 \mathrm{~Hz}$, $\left.\mathrm{H}-2^{\prime}\right), \delta 7.71\left(1 \mathrm{H}, d, J=2.35,8.7 \mathrm{~Hz}, \mathrm{H}-6^{\prime}\right)$, which were in accordance with a luteolin derivative [23]. The ${ }^{13} \mathrm{C}$ NMR values for compound 1 (Table 2) were assigned on the basis of ${ }^{1} J_{\mathrm{CH}},{ }^{2} J_{\mathrm{CH}},{ }^{3} J_{\mathrm{CH}}$ and ${ }^{4} J_{\mathrm{CH}}$ correlations observed in the HSQC and HMBC spectra. The downfield carbon data for C-6, C-8 as well as the significantly downfield shifts of H-6 and H-8 strongly indicated the presence of an electron withdrawing sulphate ester in position C-7. Similarly, a second sulphate group was indicated by the NMR values of the protons H-2', H-5' and

Table 2. ${ }^{1} \mathrm{H}(600.13 \mathrm{MHz})$ and ${ }^{13} \mathrm{C}(150.90 \mathrm{MHz}) \mathrm{NMR}$ data for luteolin 7,3'-disulphate (1), luteolin 7-O- $\beta$-(6"-malonyl)glucoside (5) and chrysoeriol 7-sulphate (7), isolated from Zostera marina leaves. Compounds were dissolved in $d_{6^{-}}$ DMSO at $25^{\circ} \mathrm{C}$.

\begin{tabular}{|c|c|c|c|c|c|c|c|c|c|}
\hline & \multicolumn{3}{|c|}{1} & \multicolumn{3}{|c|}{7} & \multicolumn{3}{|c|}{5} \\
\hline & ${ }^{13} \mathrm{C}$ & ${ }^{1} \mathrm{H}$ & $\mathrm{J}(H z)$ & ${ }^{13} \mathrm{C}$ & ${ }^{1} \mathrm{H}$ & $\mathbf{J}(H z)$ & ${ }^{13} \mathrm{C}$ & ${ }^{1} \mathrm{H}$ & $\mathrm{J}(H z)$ \\
\hline 2 & 164.0 & & & 164.0 & & & 164.3 & & \\
\hline 3 & 103.0 & 6.74 & $s$ & 103.4 & 6.98 & $s$ & 103.1 & 6.74 & $s$ \\
\hline 4 & 181.9 & & & 182.0 & & & 181.8 & & \\
\hline 5 & 160.4 & & & 160.3 & & & 161.6 & & \\
\hline 6 & 102.2 & 6.57 & $d(2.1)$ & 102.3 & 6.56 & $d(2.1)$ & 99.30 & 6.44 & $d(2.1)$ \\
\hline 7 & 159.3 & & & 159.6 & & & 162.5 & & \\
\hline 8 & 97.7 & 6.98 & $d(2.0)$ & 97.9 & 7.04 & $d(2.1)$ & 94.6 & 6.76 & $d(2.2)$ \\
\hline 9 & 156.1 & & & 156.3 & & & 156.8 & & \\
\hline 10 & 105.4 & & & 105.7 & & & 105.3 & & \\
\hline $1^{\prime}$ & 120.3 & & & 121.4 & & & 121.3 & & \\
\hline $2^{\prime}$ & 120.3 & 7.93 & $d(2.3)$ & 110.2 & 7.58 & $d(2.1)$ & 113.5 & 7.42 & $d(2.2)$ \\
\hline $3^{\prime}$ & 141.3 & & & 147.7 & & & 145.9 & & \\
\hline $4^{\prime}$ & 153.7 & & & 150.6 & & & 146.9 & & \\
\hline $5^{\prime}$ & 117.3 & 6.99 & $d(8.3)$ & 115.6 & 6.94 & $d(8.3)$ & 115.9 & 6.90 & $d(8.4)$ \\
\hline $6^{\prime}$ & 123.4 & 7.71 & $d d(8.7,2.3)$ & 120.4 & 7.60 & $d d(8.3,2.2)$ & 119.0 & 7.45 & $d d(8.4,2.2)$ \\
\hline $\mathrm{OCH}_{3}$ & & & & 56.0 & 3.89 & & & & \\
\hline \multicolumn{10}{|l|}{ Sugar } \\
\hline $1 "$ & & & & & & & 101.3 & 5.12 & $d(7.6)$ \\
\hline $2 "$ & & & & & & & 74.6 & 3.59 & $m$ \\
\hline $3 "$ & & & & & & & 77.7 & 3.58 & $m$ \\
\hline $4 "$ & & & & & & & 71.1 & 3.47 & $d d(8.7,9.4)$ \\
\hline $5^{\prime \prime}$ & & & & & & & 75.5 & 3.86 & $m$ \\
\hline $6 \mathrm{~A}^{\prime \prime}$ & & & & & & & 65.3 & 4.61 & $d d(2.1,11.7)$ \\
\hline $6 \mathrm{~B}^{\prime \prime}$ & & & & & & & 65.3 & 4.41 & $d d(6.6,11.7)$ \\
\hline \multicolumn{10}{|l|}{ Acyl } \\
\hline $1^{\prime \prime \prime}$ & & & & & & & 168.5 & & \\
\hline $2 \mathrm{~A}^{\prime \prime}$ & & & & & & & 52.7 & 3.71 & $s$ \\
\hline $2 \mathrm{~B}^{\prime \prime \prime}$ & & & & & & & 52.7 & 3.81 & $s$ \\
\hline $3 " '$ & & & & & & & 169.2 & & \\
\hline
\end{tabular}


H-6', and the carbons C-2', C-5' and C-6', which were significantly shifted downfield when compared to the corresponding proton and carbon signals of luteolin. When compared to the carbon and proton values in luteolin 7,4'-disulphate [24], the same pattern can be seem, however in compound 1, the protons and carbons in the 1', 3' and 5'-position were shifted downfield, due to the sulphate ester group in position 3'. Compound $\mathbf{1}$ is therefore identified as luteolin 7,3'-disulphate. The high resolution mass spectrum of $\mathbf{1}$ showed a positive molecular ion $[\mathrm{M}+\mathrm{H}]^{+}$at $\mathrm{m} / \mathrm{z} 446.9725$ (Table 1 ), which confirms the identity of $\mathbf{1}$. The observed fragments at $\mathrm{m} / \mathrm{z} 367.0143$ and 287.0578 indicating loss of one and two sulphate groups, were in accordance with luteolin 7-sulphate and luteolin, respectively.

The ${ }^{1} \mathrm{H}$ NMR spectrum of compound 7 showed signals for a pair of meta coupled protons at $\delta 6.56(1 \mathrm{H}, d$, $J=2.06 \mathrm{~Hz}, \mathrm{H}-6)$ and $\delta 7.04(1 \mathrm{H}, d, J=2.09 \mathrm{~Hz}, \mathrm{H}-8)$, a one proton doublet at $\delta 6.94(1 \mathrm{H}, d, J=8.29 \mathrm{~Hz}$, $\left.\mathrm{H}^{-} 5^{\prime}\right)$, a one proton doublet at $\delta 7.58\left(1 \mathrm{H}, d, J=2.07 \mathrm{~Hz}, \mathrm{H}-2^{\prime}\right)$, a one proton double doublet at $\delta 7.60(1 \mathrm{H}$, $\left.d d, J=2.14,8.28 \mathrm{~Hz}, \mathrm{H}-6^{\prime}\right)$, a one proton singlet at $\delta 6.98(\mathrm{H}-3)$, and a methoxy group at $\delta 3.89$, corresponding to a diosmetin derivative [25]. The downfield shifts of protons H-6 and H-8 and carbon C-6 and C-8 were indicating a sulphate ester linked to the 7-position. The NMR data (Table 2) were partially in accordance with previously published NMR data on diosmetin 7-sulphate [25], but whereas the methoxy group on the B ring is in the C-4' position in diosmetin, the HMBC spectrum of compound 7 showed a long-range correlation between the methoxy protons $(\delta 3.89)$ and C-3' $(\delta 147.7)$, which verified that the methoxy group was in the C-3' position. This means that the identity of compound 7 is chrysoeriol 7-sulphate, which was confirmed by HRLC-MS results showing a $[\mathrm{M}+\mathrm{H}]^{+}$at $\mathrm{m} / \mathrm{z} 381.0283$ and a fragment at $\mathrm{m} / \mathrm{z} 301.0719$, corresponding to chrysoeriol 7-sulphate and chrysoeriol, respectively. Luteolin 7,3'-disulphate (1) and chrysoeriol 7-sulphate (7) have as far as we know only been reported to be in Z. marina previously [6], but these compounds have not been completely assigned with NMR data before.

The ${ }^{1} \mathrm{H}$ NMR spectrum of compound 5 showed six proton signals in the aromatic region; $\delta 6.44(1 \mathrm{H}, d, J=$ $2.10 \mathrm{~Hz}, \mathrm{H}-6)$ and $\delta 6.76(1 \mathrm{H}, \mathrm{d}, J=2.18 \mathrm{~Hz}, \mathrm{H}-8)$, a one proton singlet at $\delta 6.74(\mathrm{H}-3)$, and an AMX system at $\delta 6.90\left(1 \mathrm{H}, d, J=8.36 \mathrm{~Hz}, \mathrm{H}-5^{\prime}\right), \delta 7.42\left(1 \mathrm{H}, d, J=2.20 \mathrm{~Hz}, \mathrm{H}-2^{\prime}\right), \delta 7.45\left(1 \mathrm{H}, d d, J=2.20,8.38 \mathrm{~Hz}, \mathrm{H}-6^{\prime}\right)$, consistent with a luteolin derivative [23]. The sugar region of 5 showed the presence of one unit. The ${ }^{1} \mathrm{H}$ and ${ }^{13} \mathrm{C}$ values of this sugar unit were assigned by a combination of $1 \mathrm{D}{ }^{1} \mathrm{H}$ NMR, 2D COSY, TOCSY and HSQC experiments. The ${ }^{1} \mathrm{H}$ and ${ }^{13} \mathrm{C}$ resonances were in accordance with $\beta$-glucopyranose [26]. A long range coupling between the $\mathrm{C}-7$ of the aglycone and the anomeric proton of the glucose unit confirmed the site of glucosylation to be at the 7-hydroxyl. The downfield shift values of H-6A" ( $\delta 4.61)$ and H-6B" ( $\delta 4.39)$ indicated acylation of the 6 "-hydroxyl, and a long range coupling between the H-6" protons of the sugar and a carbonyl carbon (C-1"') at $\delta$ 168.5 (C-1"') was observed. Furthermore, there was a cross peak at $\delta 3.71 / 168.5\left(\mathrm{H}-2 \mathrm{~A} " \mathrm{\prime \prime} / \mathrm{C}-1{ }^{\prime \prime \prime}\right)$ and $\delta 3.81 / 169.2$ (H-2B"'/C-3"') in the HMBC spectrum, corresponding to a malonyl unit. The molecular ion $[\mathrm{M}+\mathrm{H}]^{+}$at $\mathrm{m} / \mathrm{z}$ 535.1080 in the HRLC-MS of compound 5 confirmed the identity to be luteolin 7-O- $\beta$-(6"-malonyl) glucopyranoside. Luteolin 7-O- $\beta$-(6"-malonyl)glucopyranoside has been identified in terrestrial plants previously [27] [28], but this is the first time it has been reported in Z. marina. Malonylated flavone glucosides have just recently been reported to occur in marine environments [29].

\subsection{NMR Characteristics of Sulphated Flavones}

Despite the lack of NMR resonances of the sulphate moieties in sulphated flavonoids in ${ }^{1} \mathrm{H}$ and ${ }^{13} \mathrm{C}$ NMR spectra, the linkage position of potential sulphate groups might be revealed by comparison of their spectra with spectra of their non-sulphated analogs (Table 3). As described previously [12], protons and carbons in orto and para positions to the sulphate ester have higher chemical shift values than their corresponding protons and carbons of the aglycone, due to decreased shielding, whereas the carbon directly attached to the sulphate ester and the carbons in meta position have lower chemical shifts, due to increased shielding from the electron withdrawing sulphate ester. Both protons and carbons in positions 6,8 and 10 on the A-ring in $\mathbf{1 , 4}$ and $\mathbf{7}$ have significantly higher chemical shifts than in their corresponding aglycones (Table 3), which confirm that 1,4 and 7 have a sulphate group connected to C-7. The HSQC spectrum of $\mathbf{4}$ is presented in Figure 4, and illustrates the downfield shifts of C-6 and C-8 as a result of introducing a sulphate group onto the A-ring. The carbon signals of the sulphated flavones are displayed in black, whereas the signals of the corresponding aglycone, due to loss of sulphate group, are displayed in grey.

Similar NMR shift effects were revealed caused by sulphation of the B-ring of $\mathbf{1}$. A significant increase in the 
Table 3. Diagnostic ${ }^{13} \mathrm{C}$ and ${ }^{1} \mathrm{H}$ NMR sulphation shifts ${ }^{1}$ from spectra of luteolin 7,3'-disulphate (1), luteolin 7-sulphate (4) and chrysoeriol 7-sulphate (8).

\begin{tabular}{|c|c|c|c|c|c|c|c|c|c|}
\hline \multirow{3}{*}{$\begin{array}{l}{ }^{13} \mathrm{C} \\
\text { Ipso }\end{array}$} & \multicolumn{9}{|c|}{ Position of sulphation } \\
\hline & \multicolumn{2}{|c|}{$7(1,4,7)$} & \multicolumn{2}{|c|}{$3^{\prime}(\mathbf{1})$} & \multirow{2}{*}{$\begin{array}{c}{ }^{1} \mathrm{H} \\
\text { Ipso }\end{array}$} & \multicolumn{2}{|c|}{$7(1,4,7)$} & \multicolumn{2}{|c|}{$3^{\prime}(\mathbf{1})$} \\
\hline & -4.4 to -4.7 & (C-7) & -4.5 & $\left(C-3^{\prime}\right)$ & & & & & \\
\hline \multirow[t]{2}{*}{ Orto } & +3.4 to +3.6 & (C-6) & +7.1 & $\left(\mathrm{C}-2^{\prime}\right)$ & Orto & +0.3 to +0.4 & (H-6) & +0.5 & (H-2') \\
\hline & +3.6 to +3.9 & (C-8) & +4.0 & $\left(\mathrm{C}-4^{\prime}\right)$ & & +0.5 to +0.6 & $(\mathrm{H}-8)$ & - & \\
\hline \multirow[t]{2}{*}{ Meta } & -1.0 to -2.2 & $(\mathrm{C}-5)$ & -0.7 & $\left(\mathrm{C}-1^{\prime}\right)$ & Meta & & & +0.1 & $\left(H-5^{\prime}\right)$ \\
\hline & -0.8 to -1.1 & (C-9) & +0.6 & $\left(\mathrm{C}-5^{\prime}\right)$ & & & & & \\
\hline Para & +1.9 to +2.1 & $(\mathrm{C}-10)$ & +4.3 & $\left(\mathrm{C}-6^{\prime}\right)$ & Para & & & +0.3 & $\left(\mathrm{H}-6^{\prime}\right)$ \\
\hline
\end{tabular}

${ }^{1} \delta$ (sulphated flavonoid)- $\delta$ (aglycone) (in ppm).

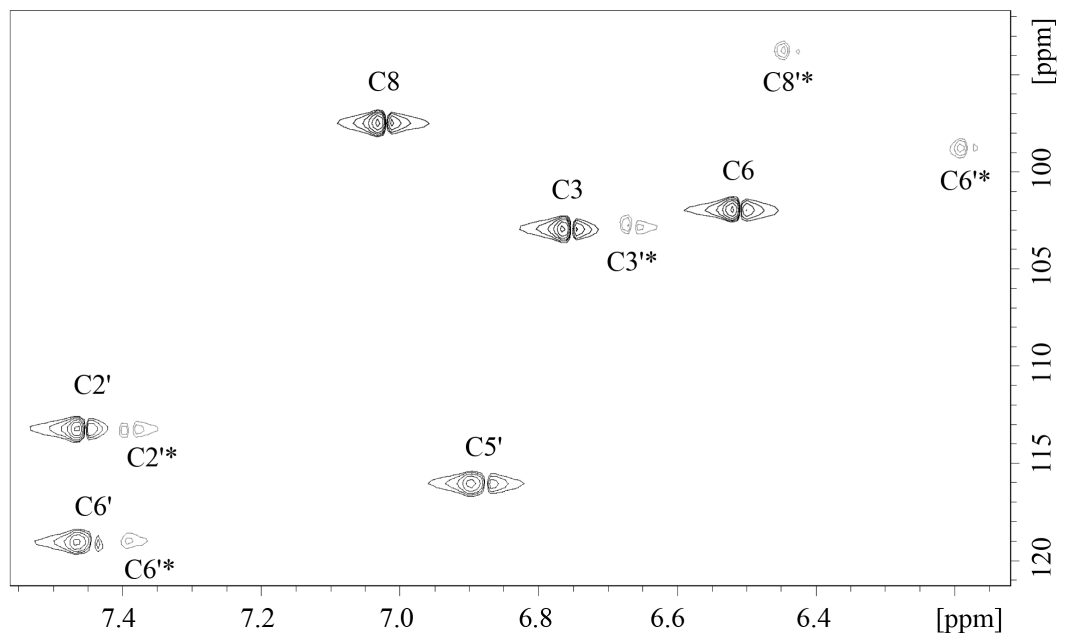

Figure 4. HSQC spectrum of compound 4 (luteolin 7-sulphate) in a mixture with 9 (luteolin). The cross peaks from compound $\mathbf{9}$ due to decomposing of $\mathbf{4}$ are shown in grey and are assigned with ${ }^{*}$.

shift values of C-2', C-4' and C-6', as well as a decrease in the chemical shift value of C-3' were observed, due to a sulphate ester group in the 3'-position on the B-ring. The increase in the chemical shift values of H-2' and H-6' were also in accordance with a sulphate ester in the 3'-position. The sulphate group induced shifts in 7 -sulphate and 7,3'-disulphate of luteolin are illustrated in Figure 5, in which ${ }^{1} \mathrm{H}$ NMR spectra of both mono- and disulphated luteolin and luteolin are displayed. The instability of sulphated flavonoids becomes evident in this illustration, as signals corresponding to luteolin can be seen in the spectrum of luteolin 7-sulphate (4), due to loss of the sulphate group. It is also possible to see some weak proton signals of luteolin 7,3'-disulphate in the spectrum of luteolin (9), which is due to the fact that the original NMR sample contained exclusively the disulphate, yet the disulphate rapidly decomposed to luteolin during concentration of the sample.

\section{Conclusion}

After optimization of extractions conditions two sulphated flavones: luteolin 7,3'-disulphate and chrysoeriol 7-sulphate were isolated and identified on the basis of NMR and high resolution mass spectra data as well as hydrolysis studies. This is the first report with complete NMR data for these two compounds, and chemical shift variations created by the sulphate groups were observed. All the sulphated flavones found in Zostera marina were shown to be easily hydrolyzed during extraction, isolation and examination unless careful handling was performed. Luteolin 7-O- $\beta-(6 "$-malonyl)glucoside was isolated and identified for the first time in $Z$. marina. Trace amounts of the malonylated flavone glucosides of apigenin and chryseriol/diosmetin previously not reported in Z. marina, were found in extracts by HRLC-MS. 


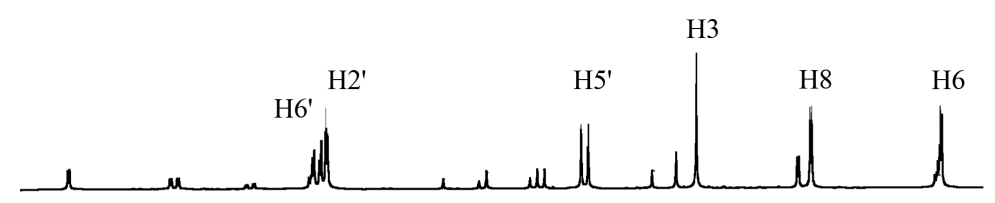

(a)

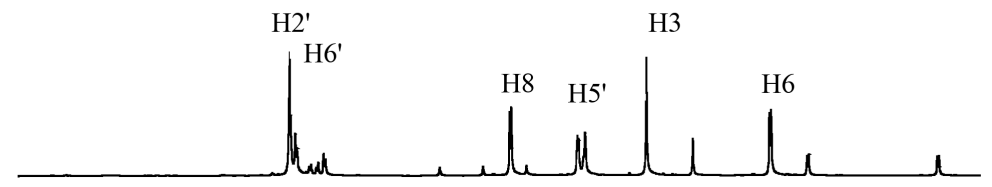

(b)

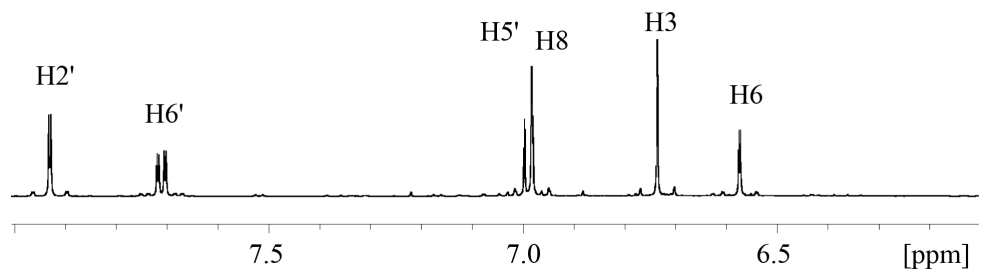

(c)

Figure 5. (a) ${ }^{1} \mathrm{H}$ NMR spectrum of 9 (luteolin), (b) ${ }^{1} \mathrm{H}$ NMR spectrum of 4 (luteolin 7-sulphate), (c) ${ }^{1} \mathrm{H}$ NMR spectrum of 1 (luteolin 7,3'-disulphate).

\section{Acknowledgements}

The authors are grateful to Associate Professor Inga Kjersti Sjøtun (Department of Biology, University of Bergen, Norway) for assisting in collecting and identifying the plant material and chef engineer PhD Bjarte Holmelid (Department of Chemistry, University of Bergen, Norway) for recording the high-resolution mass spectra.

\section{References}

[1] Borum, J. and Greve, T.M. (2004) The Four European Seagrass Species. In: Borum, J., Duarte, C.M., Krause-Jensen, D. and Greve, T.M., Eds., European Seagrasses: An Introduction to Monitoring and Management, EU Project Monitoring and Managing of European Seagrasses (M\&MS), 88. http://www.seagrasses.org

[2] Subhashini, P., Dilipan, E., Thangaradjou, T. and Papenbrock, J. (2013) Bioactive Natural Products from Marine Angiosperms: Abundance and Functions. Natural Products and Bioprospecting, 3, 129-136. http://dx.doi.org/10-1007/s13659-013-0043-6

[3] Bekkby, T., Bodvin, T., Bøe, R., Moy, F.E., Olsen, H. and Rinde, E. (2011) National Program for Mapping and Monitoring of Marine Biodiversity in Norway. Final Report for the Period 2007-2010. Norwegian Institute for Water Research Rep 6105, NIVA, Oslo.

[4] Olsen, J.L., Coyer, J.A., Stam, W.T., Moy, F.E., Christie, H. and Jørgensen, N.M. (2013) Eelgrass Zostera marina Populations in Northern Norwegian Fjords Are Genetically Isolated and Diverse. Marine Ecology Progress Series, 486, 121-132. http://dx.doi.org/10.3354/meps10373

[5] Papenbrock, J. (2012) Highlights in Seagrasses' Phylogeny, Physiology, and Metabolism: What Makes Them Special? Botany, 2012, 1-15. http://dx.doi.org/10.5402/2012/103892

[6] Harborne, J.B. and Williams, C.A. (1976) Occurence of Sulphated Flavones and Caffeic Acid Esters in Members of the Fluviales. Biochemical Systematics and Ecology, 4, 37-41. http://dx.doi.org/10.1016/0305-1978(76)90007-7

[7] Harborne, J.B. (1975) Flavonoid Sulphates: A New Class of Sulphur Compounds in Higher Plants. Phytochemistry, 14, 1147-1155.http://dx.doi.org/10.1016/S0031-9422(00)98585-6

[8] Correia-da-Silva, M., Sousa, E. and Pinto, M.M. (2014) Emerging Sulfated Flavonoids and Other Polyphenols as Drugs: Nature as an Inspiration. Medicinal Research Reviews, 34, 223-279. http://dx.doi.org/10.1002/med.21282

[9] Sousa, M.E., Correia-da-Silva, M. and Pinto, M.M.M. (2008) Sulfated Flavonoids: Nature Playing with the Hydrophilic-Hydrophobic Balance. In: Brahmachari, G., Ed., Natural Products: Chemistry, Biochemistry and Pharmacology, Narosa Publishing House, New Delhi, 392-416.

[10] Buchanan, B., Gruissem, W. and Jones, R.L. (2015) Biochemistry and Molecular Biology of Plants. Wiley Blackwell, Oxford, 763. 
[11] Teles, Y.C.F., Horta, C.C.R., Agra, M.F., Siheri, W., Boyd, M., Igoli, J.O., et al. (2015) New Sulphated Flavonoids from Wissadula periplocifolia (L.) C. Presl (Malvaceae). Molecules, 20, 20161-20172. http://dx.doi.org/10.3390/molecules201119685

[12] Barron, D., Varin, L., Ibrahim, R.K., Harborne, J.B. and Williams, C.A. (1988) Sulphated Flavonoids: An Update. Phytochemistry, 27, 2375-2359. http://dx.doi.org/10.1016/0031-9422(88)87003-1

[13] Harborne, J.B. and Williams, C.A. (2000) Advances in Flavonoid Research since 1992. Phytochemistry, 55, $481-504$. http://dx.doi.org/10.1016/S0031-9422(00)00235-1

[14] Tapas, A.R., Sakarkar, D.M. and Kakde, R.B. (2008) Flavonoids as Nutraceuticals: A Review. Tropical Journal of Pharmaceutical Research, 7, 1089-1099. http://dx.doi.org/10.4314/tjpr.v7i3.14693

[15] Yao, L.H., Jiang, Y.M., Shi, J., Tomas-Barberan, F.A., Datta, N., Singanusong, R. and Chen, S.S. (2004) Flavonoids in Food and Their Health Benefits. Plant Foods for Human Nutrition, 59, 113-122.

[16] Cushnie, T.P. and Lamb, A.J. (2011) Recent Advances in Understanding the Antibacterial Properties of Flavonoids. International Journal of Antimicrobial Agents, 38, 99-107. http://dx.doi.org/10.1016/j.ijantimicag.2011.02.014

[17] Cazarolli, L.H., Zanatta, L., Alberton, E.H., Figueiredo, M.S., Folador, P., Damazio, R.G., et al. (2008) Flavonoids: Prospective Drug Candidates. Medicinal Chemistry, 8, 1429-1440. http://dx.doi.org/10.2174/138955708786369564

[18] Lin, J.-K. and Weng, M.-S. (2006) Flavonoids as Nutraceuticals. In: Grotewold, E., Ed., The Science of Flavonoids, Springer Science, New York.

[19] Shashank, K. and Pandey, A.K. (2013) Chemistry and Biological Activities of Flavonoids: An Overview. The Scientific World Journal, 2013, 1-16. http://dx.doi.org/10.1155/2013/162750

[20] Popov, A.M., Krivoshapko, O.N. and Artyukov, A.A. (2011) Comparative Estimation of Pharmacological Activities of Luteolin and Luteolin 7,3'-Disulphate in Different Modelled Pathologies. Biofarmatsevticheskii Zhurnal, 3, 27-33.

[21] Krylova, N.V., Popov, A.M., Leonova, G.N., Artyukov, A.A. and Maistrovskaya, O.S. (2011) Comparative Study of Antiviral Activity of Luteolin and Luteolin 7,3'-Disulphate. Antibiotiki i Khimioterapiya, 56, 7-10.

[22] Markham, K.R. (1982) Techniques of Flavonoid Identification. Academic Press, London.

[23] Feeny, P., Sachdev, K., Rosenberry, L. and Carter, M. (1988) Luteolin 7-O-(6"-O-Malonyl)- $\beta$-D-Glucoside and TransChlorogenic Acid: Oviposition Stimulants for the Black Swallowtail Butterfly. Phytochemistry, 27, 3439-3448. http://dx.doi.org/10.1016/0031-9422(88)80745-3

[24] Barron, D. and Ibrahim, R.K. (1987) Synthesis of Flavonoid Sulfates: 1. Stepwise Sulfation of Positions 3, 7 and 4' Using N,N'-Dicyclohexylcarbodiimide and Tetrabutylammonium Hydrogen Sulfate. Tetrahedron, 43, 5197-5202. http://dx.doi.org/10.1016/S0040-4020(01)87695-X

[25] Grignon-Dubois, M. and Rezzoni, B. (2012) First Phytochemical Evidence of Chemotypes for the Seagrass Zostera Noltii. Plants, 1, 27-38. http://dx.doi.org/10.3390/plants1010027

[26] Jordheim, M., Andersen, Ø., M., Nozzolillo, C. and Amiguet, V.T. (2009) Acylated Anthocyanins in Inflorescence of Spider Flower (Cleome hassleriana). Phytochemistry, 70, 740-745. http://dx.doi.org/10.1016/j.phytochem.2009.03.017

[27] Lin, L.-Z. and Harnly, J.M. (2010) Identification of the Phenolic Components of Chrysanthemum Flower (Chrysanthemum morifolium Ramat). Food Chemistry, 120, 319-326. http://dx.doi.org/10.1016/j.foodchem.2009.09.083

[28] Takeda, K., Harborne; Jeffrey B. and Waterman, P.G. (1993) Malonylated Flavonoids and Blue Flower Colour in Lupin. Phytochemistry, 34, 421-423. http://dx.doi.org/10.1016/0031-9422(93)80021-J

[29] Bitam, F., Ciavatta, M.L., Carbone, M., Manzo, E., Mollo, E. and Gavagnin, M. (2010) Chemical Analysis of Flavonoid Constituents of the Seagrass Halophila stipulacea: First Finding of Malonylated Derivatives in Marine Phanerogams. Biochemical Systematics and Ecology, 38, 686-690. http://dx.doi.org/10.1016/j.bse.2010.04.007 